\title{
MARCA PRÓPRIA: INVESTIGAÇÃO DOS CONSTRUTOS INFLUENCIADORES DO DESEMPENHO EM VENDAS ${ }^{1}$
}

Rhubens Ewald Moura Ribeiro - UNIFSA, Taniele Oliveira Barbosa - UNIFSA²

\section{RESUMO}

A qualidade no atendimento ao cliente é um dos principais diferenciais para o sucesso de qualquer organização. Além disso, a mesma tem grande importância para definir o nível do atendimento e satisfação do cliente. A organização que não busca lapidar os fatores que afetam o atendimento e desempenho nas vendas está sujeita a não fidelização e a perda dos seus clientes para a concorrência. Atender com excelência é conhecer a necessidade do cliente e estar disposto a atendê-la. É saber que cada cliente é único e não adianta padronizá-lo. Têm-se como objetivo geral, analisar como a autoeficácia, a competitividade, o esforço e o atendimento relacionam-se com o desempenho em vendas de roupas de marca própria em uma loja da fábrica, localizada em Teresina-PI. A metodologia será baseada em pesquisa analítico-descritiva, de abordagem qualitativa, com perspectiva temporal transversal, junto à técnica de coleta de dados a ser realizada por meio de pesquisa de campo com uso de pesquisa documental e observação direta, tendo como método de análise de dados a análise de conteúdo. Como resultado principal, além de alcançar o objetivo geral, espera-se propor novas estratégias concebidas de forma técnica, enraizadas em informações realísticas e peculiares à empresa objeto de estudo, visando contribuir para otimização de seu desempenho em vendas.

Palavras-Chave: Atacado. Atendimento. Desempenho. Marca própria. Vendas.

\section{INTRODUÇÃO}

A organização que não busca lapidar os fatores que afetam o desempenho em vendas está sujeita a não fidelização e a perda dos seus clientes para a concorrência. Os clientes criam expectativa em meio ao que é propagado no marketing, e se sua expectativa não for atendida, ocorre à desvalorização no processo compra e venda. Quanto mais preparado e treinado o atendente estiver, melhor será para os clientes e para a organização (BRAGA, 2014; COSTA; SANTANA; TRIGO, 2015; PEREIRA; CAPELLI, 2018).

Sabe-se que muitos clientes deixam de comprar na concorrência embora os produtos tenham qualidade semelhante. No caso da empresa objeto de estudo, ela só vende produtos de

\footnotetext{
${ }^{1}$ Trabalho apresentado no Congresso Brasileiro Ciência e Sociedade (CBCS 2019), promovido pelo Centro Universitário Santo Agostinho, de 03 a 05 de outubro de 2019, em Teresina-PI.

2 Rhubens Ewald Moura Ribeiro, Mestre em Administração - UFPR, Docente UNIFSA; Taniele Oliveira Barbosa, Graduanda em Administração - UNIFSA. 


\section{gonVersSOCIENCIA \\ -}

marca própria, sendo assim, a experiência de atendimento pode influenciar positiva ou negativamente o desempenho em vendas. O seguinte problema de pesquisa surgiu: Como a autoeficácia, a competitividade, o esforço e o atendimento relacionam-se com o desempenho em vendas de roupas de marca própria em uma loja da fábrica, localizada em Teresina-PI?

Alicerçando-se em Donassolo e Matos (2014), serão utilizados os construtos e subconstrutos como direcionadores de pesquisa, ou seja, como proposição ter-se-á como base analítica que os construtos e subconstrutos definidos pelos autores possuem relação positiva entre si e, possivelmente, sobre o atendimento que, por sua vez, tem relação com o desempenho em vendas.

Então, este trabalho tem por objetivo geral descrever os fatores que influenciam o desempenho em vendas de roupas de marca própria em uma loja da fábrica, identificar as principais estratégias de vendas utilizadas pela empresa, identificar as estratégias de marketing planejadas e utilizadas pela empresa, descrever a relação existente entre autoeficácia, competitividade, esforço e atendimento sobre o desempenho em vendas de roupas de marca própria, propor estratégias que possam contribuir para a melhoria do desempenho em vendas de roupas de marca própria em uma loja da fábrica.

A realização da pesquisa pode contribuir para a obtenção de informações sobre o comportamento dos consumidores, suas recompras ao longo do tempo e os fatores que as influenciam. Pois, a dinâmica do novo mercado cria informações de maneira quase que instantânea, ocasionando na redução da capacidade de controle da empresa sobre o comportamento do cliente, surgindo a necessidade da criação de novas estratégias de vendas para as empresas na busca por facilitar o processo de tomada de decisão de seus consumidores (BARBOZA, 2013).

Os resultados da pesquisa podem, ainda, contribuir para profissionalizar ainda mais os responsáveis pela gestão da empresa e os profissionais que lidam diretamente com as vendas. Donassolo e Matos (2014) testam em seu estudo três construtos (Figura 1) e a pesquisa aqui proposta incorpora mais um construto, o do atendimento, como fator influenciador do desempenho em vendas (Figura 2) e pretende analisar sua relação com os demais construtos. Sendo este o gap teórico foco do estudo. 


\section{CONQERESSOCIENCIA:SOCIEDADE \\ Inovação, Diversidladie e Sustentalililitaile}

O problema de pesquisa em conjunto com os objetivos a serem alcançados pela pesquisa demanda a utilização de pesquisa do tipo analítico-descritiva, de abordagem qualitativa, com perspectiva temporal transversal, tendo como estratégia de pesquisa o estudo de caso único, junto à técnica de coleta de dados a ser realizada por meio de pesquisa de campo com base em pesquisa documental e observação direta, sendo feito uso de análise de conteúdo como método de análise dos dados (BARDIN, 2009; CRESWELL, 2010; GIL, 2002, 2008; MARTINS; THEÓPHILO, 2009; YIN, 2005).

O modelo conceitual que dá base a presente pesquisa é proposto por Donassolo e Matos (2014) em um estudo com vendedores atacadistas realizado em nível nacional, conforme apresentado na figura 1.

Figura 1 - O Modelo de Krishnan, Netemeyer e Boles (2002)

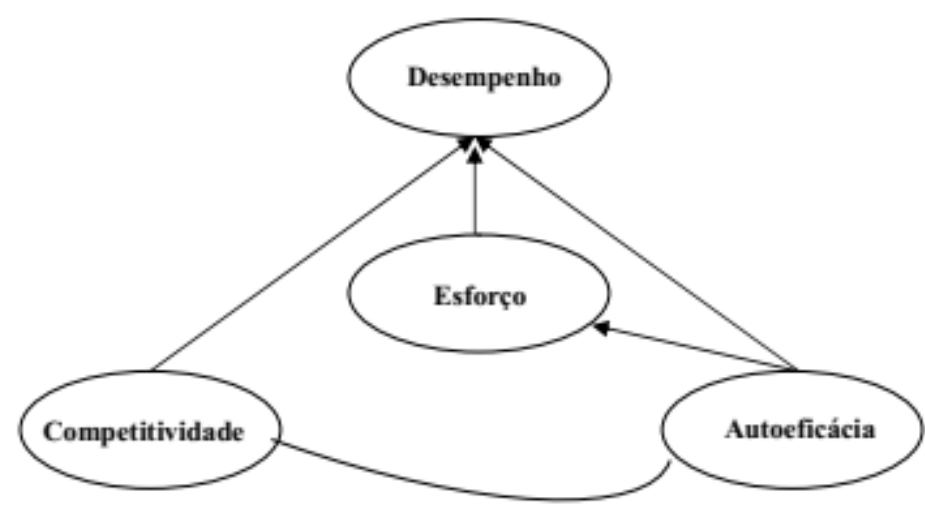

Fonte: Donassolo e Matos (2014, p. 452)

A competitividade impulsiona o indivíduo no caminho da vitória como, por exemplo, quando um vendedor deseja bater a meta de vendas antes dos demais vendedores. A autoeficácia tem a ver com a confiança em si mesmo de conseguir desenvolver uma tarefa que Ihe foi confiada ou atribuída. O esforço diz respeito ao quanto se envolve com o que se está realizando, como o tempo destinado à realização da atividade e o envolvimento com ela. Já o desempenho tem a ver com a percepção sobre o alcance dos resultados esperados ou acordados (DONASSOLO; MATOS, 2014). 


\section{congeESSOC CIENCIAESOCIEDADE \\ Inovação, Diversidladie e Sustentalililitaile}

Com base no gap teórico foi elaborado um modelo conceitual da pesquisa (Figura 2) para nortear o desenvolvimento da pesquisa incluindo o construto atendimento para se analisar junto aos demais propostos no modelo conceitual base.

Figura 2 - Modelo Conceitual da Pesquisa

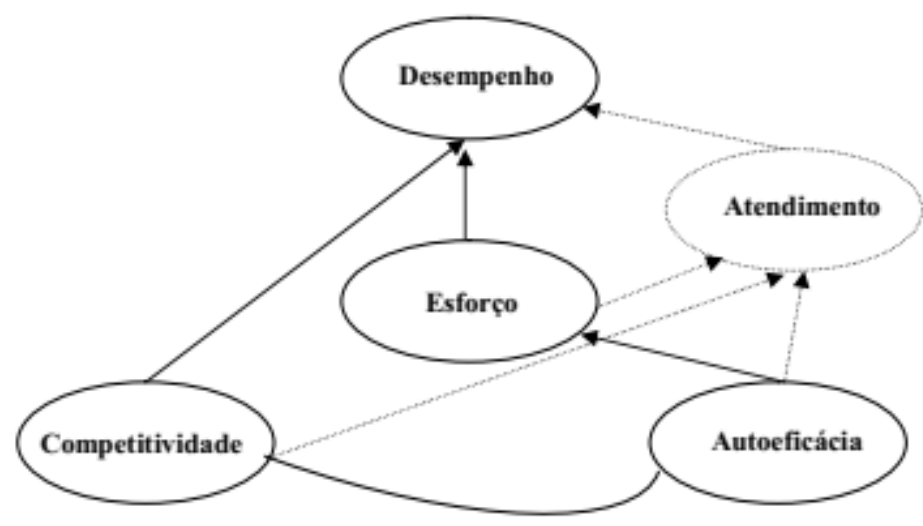

Fonte: Elaborado pelos autores com base em Donassolo e Matos (2014, p. 452)

Para isso, a pesquisa será desenvolvida em uma empresa do ramo atacadista de roupas que mantém produção e venda de roupas apenas de marca própria. Tendo como público outras empresas e pequenos empresários que trabalham no ramo de comércio de roupas. Para isso, será feito uso de pesquisa documental e observação direta como técnicas de coleta de dados para enriquecer e sanar as necessidades de dados e informações a serem analisadas para alcance dos objetivos propostos.

O desenvolvimento geral da pesquisa de campo se dará em dois momentos onde o primeiro momento será composto por pesquisa documental (Quadro 1), recolhendo dados referentes às vendas, número de clientes/compradores cadastrados em cada período, além de relatórios que se mostrem oportunos e úteis para auxiliar nas análises e inferências. 


\section{CONGGESSO CIENCIAESOCIEDADE \\ Inovação, Diversidaale e Sustentabililitaile}

\begin{tabular}{|c|c|}
\hline DOCUMENTO & DADO E/OU INFORMAÇÃO A SER COLETADA \\
\hline $\begin{array}{l}\text { Relatórios de Vendas } \\
\text { de ago de } 2018 \text { a julho } \\
\text { de } 2019\end{array}$ & $\begin{array}{l}\text { Dimensionamento da carteira de clientes } \\
\text { Parametrizar o desempenho em vendas } \\
\text { Identificar a existência de sazonalidade e seu impacto nas vendas }\end{array}$ \\
\hline $\begin{array}{l}\text { Relatórios de } \\
\text { Financeiros de ago de } \\
2018 \text { a julho de } 2019\end{array}$ & $\begin{array}{l}\text { d) Parametrizar o desempenho financeiro para auxiliar na compreensão do } \\
\text { desempenho em vendas } \\
\text { e) Identificação das formas de pagamento (“P” do prazo) }\end{array}$ \\
\hline Banco de Dados & $\begin{array}{l}\text { Perfil dos clientes } \\
\text { Periodicidade de compras } \\
\text { Impacto no desempenho (ticket médio de compra) }\end{array}$ \\
\hline Relatórios Gerenciais & $\begin{array}{l}\text { i) Levantar os produtos vendidos } \\
\text { j) Identificar relação produtos vendidos X disponiveis ("P" do produto) } \\
\text { k) Identificar os preços praticados ("P" do preço) } \\
\text { l) Composição da equipe de vendas (número, aptidões, formação, } \\
\text { experiência) }\end{array}$ \\
\hline Planejamento Anual & $\begin{array}{l}\text { Estratégias de marketing utilizadas } \\
\text { Localização e layout da loja } \\
\text { Estratégias promocionais ("P" da promoção) }\end{array}$ \\
\hline Relatórios Setoriais & Relatórios setoriais do seguimento industrial (de roupas e confecções) \\
\hline
\end{tabular}

Fonte: Autoria própria (2019)

A segunda etapa da coleta de dados (Quadro 2) será feita com base em observação direta onde serão buscadas informações e dados acerca do funcionamento da organização, layout, tamanho, localização, disposição dos produtos, etc.

Quadro 2 - Protocolo de Observação Direta

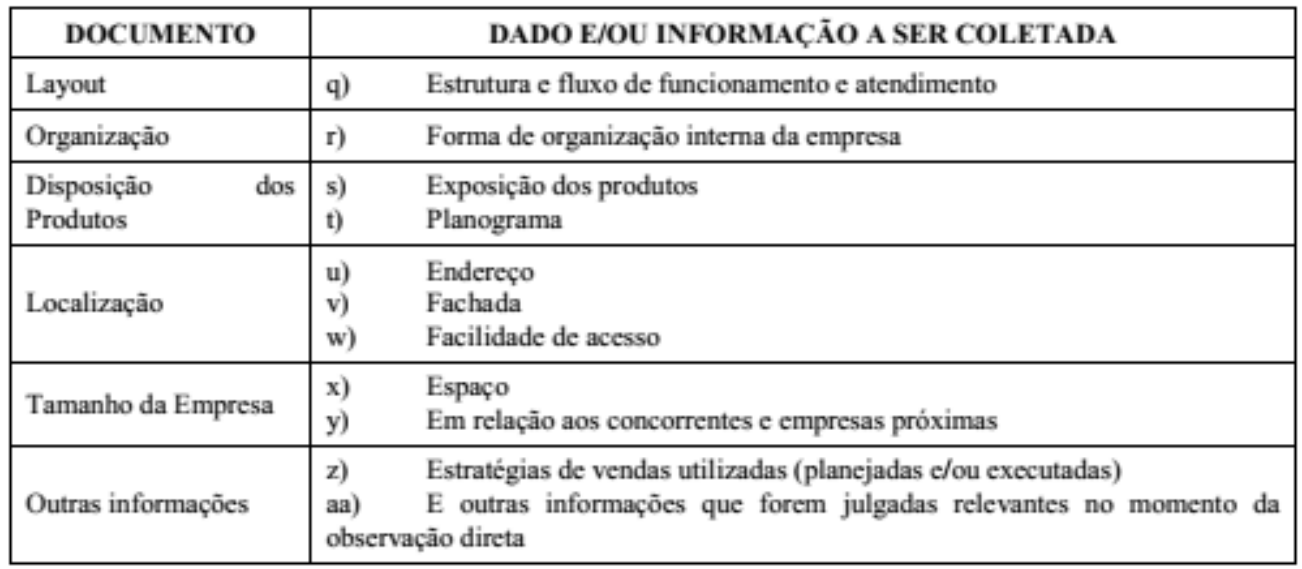

Fonte: Autoria própria (2019)

A técnica de análise de dados será a análise de conteúdo e, para isso, os dados serão organizados, tabulados e categorizados de maneira que se possam realizar inferências sobre o impacto sobre a empresa e seu desempenho, bem como relacionar as dimensões presentes no modelo conceitual de pesquisa. 


\section{CONGEFSSOCOEENCIAESOCIEDADE

A pesquisa atenderá os preceitos éticos e legais enquadrando-se nas exigências éticas para realização de pesquisa científica, de tal forma que a empresa não será identificada em qualquer parte da pesquisa ou mesmo terá seus dados divulgados de maneira irresponsável ou de forma individualizada, tendo-se sempre o cuidado para que a redação do estudo contemple o todo e análises técnicas focando na ciência.

Os riscos da pesquisa giram em torno da possibilidade de danos à dimensão física (acidente durante a coleta de dados), moral (desrespeito ou constrangimento antes, durante ou após a visita à empresa) com exposição irresponsável de informações em qualquer fase de uma pesquisa e dela decorrente por parte dos pesquisadores. Em relação aos benefícios é possível mensurar que os resultados podem permitir a compreensão de como se dá o desempenho em vendas da empresa estudada, como se relacionam os construtos e dimensões pesquisadas, e subsidiar a concepção de estratégias para otimizar o desempenho em vendas.

\section{MARKETING}

Marketing é uma palavra de origem inglesa, onde o seu significado refere-se a mercado em ação. Marketing é um conjunto de processos que envolvem a criação, a comunicação e a entrega de valor para os clientes, bem como a administração do relacionamento com eles, de modo que beneficie a organização e seu público interessado. O marketing foi criado para atender às necessidades do mercado, envolvendo a satisfação pessoal e empresarial. Nada mais é do que uma forma de promover pessoas, produtos e serviços. Os produtos necessitam de compradores, assim como uma empresa precisa de clientes (BARCELLOS, 2018).

O marketing é uma ferramenta amplamente utilizada pelas organizações, seja para promover a empresa, seja para se aproximar do cliente, seja para fortalecer sua marca, são várias as maneiras de utilizá-lo, e essa variação foi se adaptando as exigências do mercado. No surgimento do marketing sua aplicação se restringia apenas a uma estratégia de fomentar as vendas, hoje é um ponto fundamental para toda a empresa, sendo a forma mais ágil de se relacionar com o cliente, e a consolidação dessa relação é o que vai criar um diferencial competitivo para a organização (MEDEIROS, 2014). 


\section{CONOEESSOC CIENCIAESOCIEDADE \\ Inovação, Diversidaale e Sustentahilitilade}

O marketing diferencia os produtos e serviços para o seu público alvo, adaptando-se a cada perfil do consumidor, para assim atender de forma satisfatória os seus clientes. E nesse meio, as organizações promovem propostas e possíveis lançamentos para o seu futuro consumidor analisar, buscando o melhor para o seu cliente, atendendo a todas as suas necessidades (LIMA, 2015).

\section{ESTRATÉGIAS DE MARKETING}

Entende-se por marketing estratégico o processo de análise de oportunidades, escolha de objetivos, desenvolvimento de estratégias, formulação de planos e execução de implementação e do controle. É um conjunto de medidas e técnicas adotadas pela organização para atender as necessidades dos clientes como também tornar a empresa competitiva, buscando se adaptar e crescer dentro do mercado (KOTLER, 1976).

Os estudos do processo de estratégia de marketing podem contribuir com o entendimento de fatores associados ao processo de estratégia a fim de produzir melhores resultados à organização. Especificamente, a contribuição está na compreensão de como as atividades do processo, de forma independente, podem favorecer a eficácia da estratégia de marketing (FINOTI, 2018).

A estratégia de marketing indiferenciado considera que o mercado é homogêneo em relação às suas características e necessidades. A empresa pode oferecer um marketing mix sem nenhuma diferenciação. Considerando a Teoria de Maslow, pode-se empregar esta estratégia para produtos e serviços que atendem às necessidades básicas, como água, por exemplo, e a prestação de serviços gerais (KUAZAQUI, 2015).

\section{OS 4P'S DO MARKETING}

O marketing global envolve decisões da empresa relacionadas à padronização do mix de marketing (produto, preço, praça e promoção). Estas atividades podem ser concentradas em poucos países, de forma coordenada. A participação de mercado pode ser medida localmente, ou considerando o mundo como um grande mercado, sendo medida a participação global. E os 


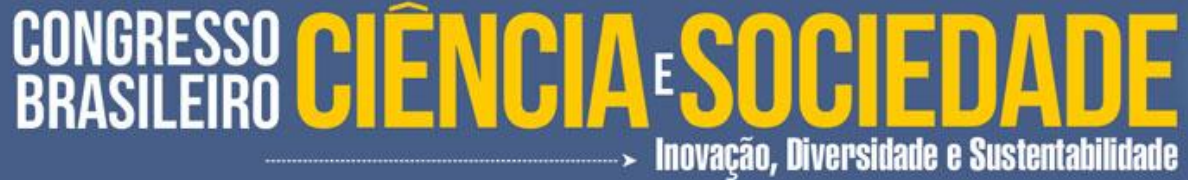

movimentos que a multinacional vai fazer globalmente podem integrar diversos países (ROCHA, 2015).

Os 4P's fazem referência ao produto (variedade, qualidade, design, garantia, etc), preço (descontos, prazo de pagamento, crédito, etc), praça ou ponto de venda (canais, localização, estoque, transporte, etc) e o promoção (publicidade, força de vendas, promoção de vendas, etc) (KOTLER; KELLER, 2012).

\section{ATENDIMENTO AO CLIENTE DE ATACADO}

O atendimento no atacado em uma organização é tão importante, quanto ter produtos inovadores e de qualidade, e preços acessíveis. Conhecer as necessidades e os desejos dos clientes é uma das formas em que as organizações encontram o seu sucesso no mercado competitivo. Na busca constante pela fidelização dos consumidores, a qualidade no atendimento surge como um meio eficiente de transformação de meros consumidores em clientes fiéis à marca (GUIMARÃES, 2016).

A gestão do atendimento ao cliente ainda se mostra incipiente na realidade brasileira. $\mathrm{A}$ explicação pode estar na falta de uma cultura organizacional que valorize o atendimento e o relacionamento com o cliente, associada a uma cultura social pouco exigente. $\mathrm{O}$ que se percebe atualmente é que a construção da imagem organizacional e a construção de confiabilidade e credibilidade dependem da forma como a empresa interage com seus clientes (SOUZA, 2018).

A qualidade no atendimento tem um papel fundamental no dia a dia nas organizações, atualmente as empresas se encontram em um ambiente cada vez mais competitivo. Desenvolver bens e serviços que satisfaçam às necessidades e expectativas dos consumidores deve ser o foco das atenções de qualquer organização que queira manter rentável e competitiva frente à concorrência. $\mathrm{O}$ atendimento de qualidade é questão de sobrevivência, pois é dele que se saberá se a empresa continuará ou não no mercado (ARAÚJO, 2015).

O grande desafio que se impõe para as áreas comerciais das empresas é, portanto, o de construir e manter relacionamentos com os clientes, principalmente com aqueles de melhor potencial gerador de vendas e de lucros (INGRAM et al., 2008). A construção de relacionamentos é fundamental para competir no mundo atual e, para tanto, a empresa confia nos vendedores (JARAMILLO, MULKI, 2008). 


\section{conghESSOCIENCIAESOCIEDADE

\section{VENDAS NO ATACADO}

$\mathrm{O}$ atacado consiste no processo de venda para clientes institucionais que compram produtos e serviços para revendê-los ou como insumo para suas atividades empresariais. Para o gerenciamento adequado da força de vendas, recomenda começar por distinguir marketing e vendas. A gestão de pessoas é uma área responsável pelo capital humano das organizações, utilizando-se dos processos de agregar, aplicar, recompensar, desenvolver, manter e monitorar pessoas. Assim, para construir talentos que atinjam os objetivos individuais e organizacionais, faz uso do processo de desenvolver pessoas. É fundamental, para superar tais dificuldades, que os gestores tenham relatórios de avaliação de desempenho de todas as áreas da empresa, principalmente na área de vendas, pois elas são responsáveis pela formação da receita da empresa, e as mesmas responsáveis por gerar lucro e pagar todos os gastos (MARTINS, 2015).

\section{ANÁLISE E DISCUSSÃO DOS RESULTADOS: CONTRIBUIÇÕES E EXPECTATIVAS}

Toda empresa ao elaborar estratégias para apresentar seus produtos ao mercado deve ter uma análise clara de todos os fatores que podem influenciar o seu desempenho. A atividade empresarial deve considerar variáveis das mais diversas, bem como decisão e gerenciamento, pois o objetivo maior que permite qualquer organização ou instituição existir é para atender alguma necessidade da sociedade, a qual é constituída por pessoas. Atendendo às necessidades da sociedade a que se propôs a empresa, ela acaba por auferir lucros e prosperar. Ou seja, a atividade empresarial não deve ser desenvolvida aquém do meio ambiente que a envolve.

A realização desta pesquisa propõe a análise da relação entre competitividade, autoeficácia, esforço e atendimento sobre o desempenho em vendas em uma loja da fábrica de roupas de marca própria, pois o mercado de marca própria tem suas peculiaridades e demanda estratégicas diferenciadas. Sendo assim, conhecer os construtos que de fato influenciam o desempenho e as circunstâncias em que se dão é de suma importância estratégica para a sustentabilidade empresarial de uma empresa. 
Com o desenvolvimento desta pesquisa, objetiva-se alcançar resultados como o desenvolvimento de habilidades de pesquisa científica na aluna em âmbito do processo de graduação em administração ao mesmo tempo em que se fomenta o desenvolvimento de conhecimento científico a ser disponibilizado à sociedade.

O desenvolver do presente estudo possibilitará a ampliação das discussões sobre a relevância da área de marketing e sua contribuição para o processo de vendas de produtos e como o processo de marketing pode contribuir com o entendimento de fatores associados ao processo de concepção e execução da estratégia a fim de produzir melhores resultados à organização.

Analisar como se relacionam os construtos objeto de estudo (competitividade, autoeficácia, esforço, atendimento e desempenho em vendas) permitirá a compreensão aprofundada de peculiaridades que possam contribuir para o planejamento de ações e estratégias voltadas ao mercado de marca própria, atacadista e de roupas.

O diagnóstico de uma organização que sirva de alicerce para seu processo de planejamento contribuirá para a concepção de novas estratégias de forma técnica e que sejam enraizadas em informações realísticas e peculiares à empresa objeto de estudo, além de contribuir para a otimização de seu desempenho em vendas.

Pretende-se, ainda, criar um arcabouço teórico inicial de maneira complementar ao proposto por Donassolo e Matos (2014) para que se possa dar continuidade à presente pesquisa junto à outras organizações do mesmo ramo ou mesmo um aprofundamento e amplificação do escopo investigatório dentro da mesma empresa objeto de estudo atual, pois o cenário de negócios tem se apresentado cada vez mais complexo devido às questões políticas, sociais, concorrenciais, entre outras. Tudo isso, demanda a compreensão pormenorizada do funcionamento de uma organização e de suas estratégias de marketing que possam levá-la à maximização do sucesso em relação ao seu desempenho em vendas.

\section{REFERÊNCIAS}

ARAÚJO, W. R. S. Qualidade no atendimento aos clientes da terceira idade nos serviços prestados pelo Banco do Brasil S/A, Agência 2053, em Fagundes-PB. 2015.

BARBOZA, M. M. Relação entre o tipo de ajuste regulatório e a dificuldade da tarefa sobre avaliações de mensagens de anúncios de consumo. Curitiba, 2013. 104p. Dissertação (Mestrado 


\section{COMGERSSO CIENCIA BSA \\ -}

em Administração) Programa de Pós-graduação em Administração, Universidade Federal do Paraná, 2013.

BARCELLOS, R; SCHELELA, S. S. Marketing e Vendas. Editora FGV, 2018.

BARDIN, L. Análise de conteúdo. Edição revista e atualizada. Lisboa: Edições 70, 2009.

BRAGA, V. S. et al. Qualidade no Atendimento ao Cliente. Revista de Trabalhos Acadêmicos, 2014.

COSTA, A. S. C.; SANTANA, L. C.; TRIGO, Antônio Carrera. Qualidade do atendimento ao cliente: um grande diferencial competitivo para as organizações. Revista de Iniciação Científica-RIC Cairu, v. 2, n. 2, p. 155-172, 2015.

CRESWELL, J. W. Projeto de Pesquisa: Métodos qualitativo, quantitativo e misto.

São Paulo: Artmed. 2010.

DONASSOLO, P. H.; MATOS, C. A. Os fatores preditores do desempenho de vendas: um estudo com vendedores atacadistas. Revista Brasileira de Gestão de Negócios, v. 16, n. 52, p. 448-465, 2014. Disponível em: http://www.spell.org.br/documentos/ver/33683/os-fatores-preditores-dodesempenho-de-vendas--um-estudo-com-vendedores-atacadistas. Acesso em: 07 de fevereiro de 2019.

FINOTI, L. et al. A Influência da Inovatividade no Processo de Estratégia de Marketing e o Impacto sobre o Desempenho Organizacional: Evidências do Setor TIC. Revista Brasileira de Marketing, v. 17, n. 2, p. 166-186, 2018.

GIL, A. C. Como elaborar projetos de pesquisa. 4. ed., São Paulo, Atlas, 2002.

GIL, A. C. Métodos e técnicas de pesquisa social. 6. ed., São Paulo: Atlas, 2008.

GUIMARÃES, D. M. Diagnóstico da qualidade no atendimento ao cliente na empresa INFERRALIndústria e Comércio de Artefatos de Ferro e Alumínio. 2016.

INGRAM, T. N. et al. Gerenciamento de vendas: análise e tomada de decisão. São Paulo: Cengage Learning, 2008.

JARAMILLO, F.; MULKI, J. P. Sales effort: the intertwined roles of the leader, customers, and the salesperson. Journal of Personal Selling and Sales Management, New York, v. 28, n. 1, p. 37-51, Winter 2008.

KOTLER, P. Marketing management: analysis, planning and control. 3rd Ed. Englewoods Cliffs: Prentice-Hall, 1976

KOTLER, P; KELLER, K. L. Administração de Marketing. 14ạ Ed. Pearson, 2012. 


\section{CONGERSSOOCIENCIASSOCIEDADE \\ Inovação, Diversidaale e Sustentahilitiade}

KUAZAQUI, E. Considerações sobre o Plano de Marketing para as Microempresas Brasileiras. REMIPE-Revista de Micro e Pequenas Empresas e Empreendedorismo da Fatec Osasco, v. 1, n. 1 jan-jun, p. 3-21, 2015.

LIMA, Miguel Ferreira. Gestão de marketing. Editora FGV, 2015.

MARTINS, Carlos Alberto. Técnicas de vendas. Editora FGV, 2015.

MARTINS, G. A.; THEÓPHILO, C. R. Metodologia da investigação científica para ciências sociais aplicadas. 2. Ed., São Paulo, Atlas, 2009.

MEDEIROS, J. D. Estratégias de marketing para potencializar as vendas: o caso da Vip Calçados. 2014. Trabalho de Conclusão de Curso. Universidade Federal do Rio Grande do Norte.

PEREIRA, M. D.; CAPELLI, R. B. ESTUDO DE CASO: A excelência no atendimento ao cliente da empresa Tio Bákinas, em Goiânia/GO. QUALIA: a ciência em movimento, v. 3, n. 2, p. 123-151, 2018.

ROCHA, T. V. et al. Estratégias de marketing global na internacionalização de franquias brasileiras. Revista de Administração da UNIMEP, v. 13, n. 3, 2015.

SOUZA, I. M. Gestão do atendimento ao cliente: uma análise da Central de Relacionamento dos Correios. 2018.

YIN, R.K. Estudo de caso: planejamento e métodos. Tradução de Daniel Grassi. 3. ed., Porto Alegre, Bookman, 2005. 